This item was submitted to Loughborough's Research Repository by the author.

Items in Figshare are protected by copyright, with all rights reserved, unless otherwise indicated.

\title{
An exploration of the progress of open crime data: how do ongoing limitations with the Police.uk website restrict a comprehensive understanding of recorded crime?
}

\section{PLEASE CITE THE PUBLISHED VERSION}

https://doi.org/10.1080/10439463.2017.1397149

\section{PUBLISHER}

(C) Taylor \& Francis (Routledge)

\section{VERSION}

AM (Accepted Manuscript)

\section{PUBLISHER STATEMENT}

This work is made available according to the conditions of the Creative Commons Attribution-NonCommercialNoDerivatives 4.0 International (CC BY-NC-ND 4.0) licence. Full details of this licence are available at: https://creativecommons.org/licenses/by-nc-nd/4.0/

\section{LICENCE}

CC BY-NC-ND 4.0

\section{REPOSITORY RECORD}

Quinn, Anthony, Louise Cooke, and Mark P. Monaghan. 2019. "An Exploration of the Progress of Open Crime Data: How Do Ongoing Limitations with the Police.uk Website Restrict a Comprehensive Understanding of Recorded Crime?". figshare. https://hdl.handle.net/2134/27513. 
Title Page:

An exploration of the progress of open crime data: how do ongoing limitations with the Police.uk website restrict a comprehensive understanding of recorded crime?

Anthony Quinn, Louise Cooke and Mark Monaghan.

\begin{abstract}
:
Open source crime data provided by the Police.uk website was introduced in 2008. This provision challenged what had been termed a ‘top down' political culture and was introduced to help increase government transparency and accountability. We examine these concepts here and outline some of the significant developments over the last decade related to the information contained within the Police.uk resource. Our focus then moves towards limitations of the data set provided, some of which are as pervasive today as they were when this online data source was first introduced. We explore whether these drawbacks are irresolvable and consider the practical implications they will have when this open data set is utilised by members of the public and researchers. Ultimately, we give an assessment of the efficacy of this source of information for the user within the context of the government rhetoric which accompanied it.
\end{abstract}

Keywords:

Open Data, Police Recorded Crime, Geoprivacy, Crime Mapping, Government Accountability 


\section{Introduction:}

Since the beginning of the twenty-first century, police forces in England, Wales and Northern Ireland have utilised computer generated crime maps to facilitate analysis of where crime is being recorded (Chainey and Tompson, 2012). At the outset, the data underpinning these maps was solely for police staff but more recently a form of this information has been placed within the public domain. This information has been referred to as 'open source crime data' (Tompson et al, 2015) and is freely accessible on the Police.uk website. Here it is possible to view open crime data and related information which has been made available, in theory, as a means of keeping the public informed about police performance and priorities (UK Statistics Authority, 2010). Public access to this data, it is suggested, improves 'accountability' (Bizer, 2009) whilst also 'making police performance more transparent to the public' (Police.uk, 2016b). This has not always been widely accepted however, for instance, in 2012 it was expressed that there was little evidence attempts at increasing transparency in this way had been realised (Chainey and Tompson, 2012). Nonetheless in 2015 the then Home Secretary, Theresa May, announced that the government continues to have a commitment to increasing transparency for the public (Police.uk, 2015); a pledge that offered great potential for the movement of valuable data away from an exclusive realm to a public realm, at no cost. By examining the features of the Police.uk website and its downloadable data more closely, we hope to offer reasons how this 'transparency' may or may not have been realised.

Open crime data is currently available on the www.Police.uk website where information can be downloaded for each of the 43 police forces in England and Wales and for Northern Ireland. The website states that "the total cost of the Police.uk contract since the website was launched in January 2011 is $£ 842,128$ ’’ (Police.uk, 2016a) which equates to an average of $£ 35,089$ per month (ibid); herein we examine the content of the information provided for this cost. The publication of these crime statistics is primarily intended "to inform, engage and 
empower the public to participate in crime prevention efforts' (Chainey and Tompson 2012, cited in Tompson et al, 2015: 98) but whether these objectives can be fulfilled within the current framework is less clear. In an indictment of the initiative, Arthur (2011) reported that crime maps are often worse than useless. Although, as we shall see, in their current format there are limits to what can be learned from them, others have suggested that the development of open-source crime mapping could prove hugely beneficial in the future (see Chainey and Tompson, 2012).

The central purpose of this paper is to determine the efficacy of this open source crime data which is made available to the general public and researchers who do not have access to more detailed police recorded crime data; much of which is held on police premises. The dissemination of this information within the public domain could be described as 'citizencentred' (Shadbolt et al, 2012: 16) since its intended outcome is to improve the accountability of the public services that it involves (ibid). Citizens may want to utilise such information primarily to become aware of local levels of crime and the nature of offences concerning local policing teams (Smith and Heath, 2014). We therefore also touch upon the wider balancing act which takes place between offering enough detail to provide transparency and staying within the confines of privacy legislation; for example, the Data Protection Act 1998 which establishes regulations of how personal information can be used by organisations, businesses and the government (Legislation.gov.uk, nd).

Whilst we fundamentally agree with the principle that this could herald a new era for engagement with police recorded crime data and even crime analysis away from the traditional confines of police work, we remain sceptical about some elements of its current format. The following piece draws upon present concerns with this presentation of data alongside further limitations that might be encountered when seeking to critically examine these publicly available crime records. In doing so, the paper is organised with a brief 
explanation of what constitutes open crime data before moving to explore difficulties that might be experienced by lay members of the public and then researchers thereafter.

\section{Police.uk as a form of open data}

To assess how or even whether the supply of open data has permitted greater transparency and accountability, it is of paramount importance to establish exactly what constitutes 'open data'. Open data constitutes 'non-privacy-restricted and non-confidential data which is produced with public money and is made available without any restrictions on its usage or distribution', (Janssen et al, 2012: 258). This contrasts with the recorded crime data held on police premises which is both 'restricted' and contains confidential information about the recording and reporting of the offence. As Kounadia et al, (2013) suggest, it is thus highly unlikely that open data could be misused as might be the case with private information (Kounadia et al, 2013). A possible example of misuse would be the utilisation of crime reports by for profit organisations to target potential customers for commercial gain (ibid).

A further positive aspect of providing open data for public inspection is that it can provide a greater awareness of where, and what type of, offences have occurred. This raises the possibility for questions the public might have about recorded crime to be answered or even questions about policing and crime to be devised (Janssen et al, 2012). In effect, it could facilitate greater accountability. A further strength is that the provision of open data by governments is representative of intention to develop open system of governance (ibid); a

point also noted by Shadbolt et al, (2012). This is symbolic of a government striving towards openness and greater accountability in an 'era of freedom of information' (Cooke and Sturges, 2009). As will become clear, who this label of 'public' includes is unclear; there are clear tensions between providing sanitised and non-stigmatic data for lay members of the 
public whilst providing suitable materials for researchers within the public realm and vice versa.

In addition to open data, a plethora of crime 'Apps' (mobile applications which can be accessed on smartphones, electronic devices and online) have also been developed and which are showcased on Police.uk (2016a). These highlight how crime related information is in the process of becoming more ubiquitous (examples of the Apps are displayed by Figure 1.0). In addition, the police.uk website offers a source of information towards which police representatives can direct a member of the public when asked for subjective knowledge or opinion on the level of crime in an area. Undoubtedly this helps to maintain impartiality towards community identities; an important aspect of policing (Ericson and Haggerty, 1997). There are limitations with the data provided and the picture of crime presented is partial but there have been attempts made by the Home Office, who are responsible for publishing this open data, to disseminate useful crime data.

[Figure 1.0 near here]

\section{Interaction with Police.uk data by members of the public}

The balancing act between privacy legislation and providing transparency

In the UK, the supply of open crime data online is subject to privacy regulation. The Data Protection Act 1998 (ICO, 2012), has a significant impact on data that is made available and there are 'civil legal arrangements regulating publication and disclosure that present a barrier to organizations wishing to make information accessible to the public' (Sampson and Kinnear, 2009: 11). Ratcliffe (2002a: 10) notes that 'one point with which few people 
disagree is the notion that personal privacy should be protected'. In practical terms this means that for Police.uk data the exact location of the offence is anonymized whilst the specific crime (for example 'Vehicle Crime instead of 'Theft of a Motor Vehicle'), the modus operandi and the time and day of an offence are not disclosed. Certain crime types are aggregated together and their records are only released monthly due to what have been termed as geoprivacy concerns (Tompson et al, 2015).

Police recorded crime data supplied online is subject to rigorous anonymization before it is made public and it is more obscure than the data used by crime analysts within the police. For Tompson et al (2015), this process ensures privacy by making it difficult to recognise the details of specific crime counts based on information that might have been broadcast by the media. The anonymization of place is ensured by never placing points over specific dwellings (ibid). Instead, a master list of over 750, 000 anonymized map points is used to ensure crime dots appear over the centre point of a street and each map point covers at least eight or no postal addresses at all (Police.uk, 2016a). This is carried out in accordance with the guidelines set out by the code of practice report from the Information Commissioner's Office (Graham, 2012; see also ICO, 2012). This 'geomasking' is conducted to prevent the possibility of ‘reverse geocoding’ (Tompson et al, 2015). ‘Geomasking’ involves slightly altering the geographic coordinates of a crime point to mask the exact location of the perpetration (Kwan et al, 2004; Tompson et al, 2015). Reverse geocoding is where a crime can be traced back to an exact point where an offence was committed.

Reverse geocoding is a technique deemed to be in breach of privacy for three fundamental reasons. Firstly, it allows geographic coordinates to be taken from a map to extract textual information such as a name, address or telephone number (Kounadi et al, 2013). Secondly, 
without the implementation of geomasking, what was discovered as a mere crime point on a map could lead to a wealth of information being obtained to advance corporate interests (Poulsen and Kennedy, 2004). An example is the targeting of burglary victims as potential consumers of domestic security devices (ibid). Not only could victims be directly identified, but personal information could be sold on to third parties for other uses (Hoofnagle, 2003). This would mean that what initially originated as communication with the police to report an offence, resulted in a rather different, potentially controversial outcome. Thirdly, and arguably the most serious consequence of reverse geocoding, a form of 'spatial labelling' (Poulsen and Kennedy, 2004) could occur whereby a specific location receives unwelcome attention or stigma because of controversial crimes such as sex offences being identifiable in that area (Ratcliffe, 2002a). In the UK if further information is required about a person on the grounds of child protection concerns, there are more discrete methods to obtain this information (see Gov.uk, 2013). This is quite different from the situation in the USA where the Family Watchdog (2016) website provides detailed information if a ZIP code is typed into the search function. This information includes the exact address of where an offender resides, charges held against the individual and even a profile photo of them. Further research is needed to examine if and how transparency and privacy are balanced in other countries and what this means for the utilisation of open crime data. This could help to discern whether progress can be achieved in England, Wales and Northern Ireland with regards to offering members of the public a fuller understanding of police recorded crime.

The necessary obfuscation of data means that the potential for members of the public to hold their local police accountable is limited if they are not made aware of the complete picture of recorded crime. This is exemplified by the broad crime labels that are utilised. For instance, violent and sexual offences are classified in the same category despite encompassing various 
different types and severities of violence (Walby and Allen, 2004). The case is the same for “vehicle crime”'. Even though there are four different classifications for vehicle crime offences in England and Wales, (Home Office, 2016), only three of these receive coverage by Police.uk. The classification labelled ‘Aggravated Vehicle Taking’ is omitted. 'Aggravated Vehicle Taking' involves the theft or unauthorised taking of a vehicle as well as the injuring of a person or property (Gov.uk, 2016) and the sentence for such an offence can be up to 13 years imprisonment if the offence results in the death of another (gov.uk, nd). Less serious offences such as 'Interfering with a Motor Vehicle', which involves interfering with part of a vehicle or 'getting on to’ a vehicle (Gov.uk, 2016) for which the maximum sentence for this offence is 12 weeks imprisonment (Sentencing Council, 2017), do receive coverage. Police.uk data could if used in isolation give a false impression of the seriousness of crime in an area. Decades of research into crime and policing has established that simply summing crimes together can be misleading and that there are other important factors to consider; an assessment of the level of crime harm (Sherman et al, 2016) constitutes one of these considerations. Thus, while the Police.uk website could display high levels of vehicle crime offences within a particular area, these could quite plausibly be clustered counts of Interfering with a Motor Vehicle. What would be more problematic is if there were only a few crime counts in an area but these were counts of Aggravated Vehicle Taking where, for example, dangerous driving has occurred in stolen vehicles. Looking at crime by volume is certainly not the only way, and it is not the most reliable way (Sherman et al, 2016) to assess the risk of crime. The reason why offences have to be grouped under broad labels after being systematically geomasked is unclear. 
Practical implications with the recording of crime data

There are two key issues concerning privacy and the recording of offences that impact upon the detail of the data that can be provided. These are explored below. We provide evidence to argue that the current level of detail of open crime data hinders a true engagement and empowerment of the public (Chainey and Tompson, 2012). Common limitations with police recorded crime data affect the inspection of open data downloadable from Police.uk because 'certain types of crime are still reported to the police more than others as a result of, for example, economic and insurance incentives’ (Byrne, Evans et al, 2013: 2). This could cause some crime types to be incorrectly perceived as a more pressing concern than others (ibid). Unlike the reporting of acquisitive crimes which may be instigated by a requirement to settle insurance claims, counts of domestic violence and sexual assault are more unlikely to come to the attention of the police (Walby and Allen, 2004). It has been stated that 'only around $15 \%$ of those who experience sexual violence choose to report it to the police' (Rape Crisis England and Wales, 2016). Furthermore, in 2014 it was widely reported that 20\% of crime reported to police goes unrecorded (HMIC, 2014; BBC News, 2014) which means an investigation into these reported offences is unlikely to happen (BBC News, 2014). To further compound the issue of under-reporting for violent crimes and sexual offences (Walby and Allen, 2004), these two categories also had the highest rates of under-recording (HMIC, 2014; BBC News, 2014).

i. The utilisation of broad crime classifications.

If offences recorded by the police are not an adequate reflection of all crime types as they occur, there exists the probability that the Police.uk website underestimates the volume of some crime types. There is no mention by Police.uk (2016c) of these reporting issues in the 'known issues' section of the website. Although this might not pose a problem for those with 
previous exposure to police data or those well-schooled in criminological study; for lay members of the public, the information published by Police.uk could be misinterpreted and certain crimes overlooked despite posing an equal or more significant risk to victims or society. Presently, the open crime data provided by this website is orientated towards crime committed in public space. Information on robbery, bicycle theft and public order offences is available whilst awareness of crime types such as domestic violence is left to remain obscure; as are occupational crimes such as money laundering. Crime maps provided by Police.uk display offence counts that involved a single event such as a bicycle theft from a street bicycle stand. A count on a crime map would be suitable for understanding the proximity within which this bicycle theft offence occurred. However, even if information of more complex offences such as domestic violence was provided, it is a crime type that can involve several antecedent offences to the one reported to the police (Walby and Allen, 2004). A crime map would only display a fraction of a series of offences; whether crime maps are the most effective way to therefore display this type of victimisation is questionable. The police.uk website promises to act as a form of open government communication but in this respect, complex processes could be portrayed simplistically as one-off events.

Due to a preoccupation with more typical notions of crime and the physical space within which it occurs, issues such as cybercrime, fraud and identity theft are also overlooked (Kindynis, 2014); as are other crimes that police records could be used to address such as: Heritage Crime (Grove and Thomas, 2014), Hate Crime (Chakraborti and Garland, 2015 and State Crime (Monaghan and Prideaux, 2016). As suggested by Janssen et al (2012), if seeking to ascertain a weather forecast, only being informed of certain weather types would likely limit satisfaction. 


\section{ii. Missing data.}

Another limitation with the open data provided is that much data is likely to be missing. There are a variety of reasons why this could be, including: differences in the way crime is recorded between police forces, a more general problem of under-reporting to the police, under-recording by the police and lastly some offences do not occur at a fixed location but are treated as such. According to Police.uk (2016c), the data published on their website is provided by the British Transport Police as well as police forces in England, Wales and Northern Ireland and the Ministry of Justice. Requiring further explanation is how crime counts supplied by the British Transport Police are attributed to 'snap points’; map points which contain at least eight postal addresses (Police.uk, 2016a) generated over the centre point of a street or above a public place (Tompson et al, 2015). Certain offences recorded by the British Transport Police, which do not occur at static locations but rather during a bus or train journey, are attributed to the snap point at the end point of that journey (Police.uk, 2016a). How these points are therefore incorporated with the Police.uk crime data, which does include offences that are reported to occur at a fixed location, requires clarification. If for instance they are generated to appear at the nearest alighting point to the offence, this will impact on perceptions of offences on that street even though some of them did not necessarily occur within that vicinity. This is likely to be an issue particularly in locations with lively transport links where there are numerous snap points at the end of journeys. A case in point is shown in Figure 1.1 where there are several snap points for various transportation methods. Whilst there are numerous snap points with large volumes of incidents, it is unclear whether these scores are because of a high volume of crime on surrounding streets, a high volume of crime on nearby transport links or both of these scenarios.

\section{[Figure 1.1 near here]}


A further complication with the Police.uk data set is acknowledged on the 'changelog' section of the website and concerns issues that individual police forces face in the recording of crime. The changelog is a section where editing of the data is noted as well as any known issues encountered each month as far as the collation of data is concerned. Crime data is downloadable for forces in England, Wales and Northern Ireland and input from such a vast number of forces means that the open crime data set which aggregates this wealth of data is susceptible to inaccuracies. Furthermore, Transport for London data, and crime data recorded by other transport companies, are missing from this resource. A better impression of these inaccuracies is provided in the changelog and includes points of latitude and longitude for certain crime counts being absent from some police forces and snap points attracting excessive numbers of offences (Police.uk, 2016c).

There is also the prospect that each independent police force exercises slightly different crime recording practices. This eventuality is difficult to determine without a systematic review of how each of the forces in England, Wales and Northern Ireland records crimes. An inspection of crime data integrity has been conducted for the British Transport Police (see HMIC, 2015) and perhaps placing closer scrutiny upon how a vast array of police forces record crime constitutes an informative line of research. Undoubtedly, there are guidelines provided (see HMIC, 2016) but how well they are adhered to and whether forces sufficiently probe cases which do not seem correct remains undetermined. The National Crime Recording Standard (gov.uk, 2017) seeks to make the crime recording process victim focused and a standard by which forces are to record crime is provided. It is a standard that still requires a degree of judgement by force staff through comprehension of directions such as 'on the balance of probability' (ibid). Indeed, there is a framework by which to accurately record crime but it is conceivable that sometimes the circumstance of a crime might still be misunderstood or 
incorrectly classified. How much of this knowledge, regarding issues with police recording practices, is made publicly available is a further issue. As has been recognised, 'from deciding a crime has occurred, to reporting and recording, there are areas in which the data can mislead’ (Byrne et al, 2013: 2). Publishing a great quantity of data online does not necessarily correlate with great quality and maintaining high standards to avoid inaccuracies represents a much sterner challenge.

A third reason why data might be absent is due to the problems of under-reporting of crime to the police and under-recording of crime by the police. Although in the last decade or so there may have been an improvement in recording methods and a greater willingness to report crime (Office for National Statistics, 2016b), it seems reasonable to suggest that there still exists a dark figure of crime (MacDonald, 2002); a figure which includes all the crimes committed but not reported or recorded by the police (ibid). In 2017, it was reported that one UK police force had recorded only $75.8 \%$ of reported crime which was deemed 'inadequate' (HMICFRS, 2017). Police.uk (2016c) claims to be a 'rich data source for information including: neighbourhood team members, upcoming events and street level crime and outcome data' but disconcertingly it fails to mention the data provided only includes as many crime counts as are reported to the police and recorded correctly by the police. The information presented could be labelled as reflecting only reported crime rather than any ‘true’ measure of crime (Kindynis, 2014). Even when offences are reported to the police, there is a chance records of the offence cannot be successfully geocoded leading to a lower 'match rate' (Kounadia et al, 2013). This can occur when an offence cannot be matched to an exact location because of incorrect or absent geographical reference points. The Crime Survey for England and Wales (CSEW) (ONS, 2016a), although it might not include crime counts which can be mapped, could be used to obtain an understanding of critical issues such 
as targets susceptible to victimisation or when offences are likely to occur; yet this is information that evades mention alongside the crime data set supplied by Police.uk (2016c). Greater emphasis could be placed on the utility of the CSEW for users who wish to better understand how crime is experienced by different sections of society.

\section{Assessing public engagement}

The Police.uk (2016) website states 'the Government is committed to making police performance more transparent to the public' by adding all police and criminal justice data to the Police Recorded Crime and Police Outcomes Data already provided (ibid). This development sits alongside others such as the development of crime maps. For instance, the presentation of crime data has moved on from the police internally producing maps based on intelligence (Chainey and Tompson, 2012) and mere symbols denoting where different crime types have occurred (Weisburd and McEwen, 1998) to a public display of crime maps with the latest internet mapping technologies such as Google Maps and Bing Maps (Chainey and Tompson, 2012). A noticeable feature of the Police.uk website is the neighbourhood search function. Web users can type a postcode into a search facility in order to display how many and what type of offences occurred within the policing boundary under which the postcode falls. Offences are displayed for each month and social media profiles of the governing authorities are presented alongside current 'policing priorities of the neighbourhood'; a feature which somewhat fulfils the recommendation for police to use "social networking technology to support better engagement”' (Chainey and Tompson, 2012: 10). Social media is now frequently utilised by police in the UK to convey information (Fernandez et al, 2014) but levels of resultant engagement with these platforms by citizens is less understood. What 
might therefore be of interest on the Police.uk site is the level of engagement citizens have with the presentation of social media profiles and policing priorities as well as the crime data made available. In 2014, Smith and Heath (2014) declared that the Police.uk site had received 64 million hits since the start of 2011 however hits on the website do not necessarily equate to satisfaction with the content provided. Smith and Heath (2014) also refer to a randomised control trial undertaken in 2010 (Quinton, 2011) to support claims the provision of open crime data was well received by the public. However, one of the stated limitations of that study was that it is unlikely to be representative of the wider public (ibid). Additionally, this study did not investigate perceptions and usage of the newer version of Police.uk which means there is much scope for academic research into current satisfaction and usage of Police.uk by members of the public. It would be insightful to learn just how widespread the desire for this information is and what sections of the population it appeals to. When this is achieved, the level of accountability realised by this crime data will be more apparent.

\section{Use of Police.uk data by the research community}

There is not sufficient space here to address the entirety of the challenges facing researchers when it comes to downloading open data although the most prominent should give an understanding of a further aspect likely to limit engagement and participation (Chainey and Tompson, 2012). Since December 2008, all police forces in England and Wales have published crime statistics via the crime maps viewable on Police.uk (ibid) and this was followed by the publication of downloadable data in December, 2010 (Tompson et al, 2015). This has meant the user is no longer constrained to browsing a pre-prepared map provided by the website, but instead can now modify, plot and analyse data with the use of appropriate GIS (Geographic Information Systems) mapping software. This is a good example of the 
government attempting to ‘actively solicit feedback’ (Janssen et al, 2012: 259) in order to 'learn from the public' (ibid). On Police.uk (2016a), data is downloadable in .csv file format for all 43 police forces in England, Wales and Northern Ireland from December 2010 up until two months prior to the current month. Boundary data for each of the forces is provided on the same site (ibid) in . kml file format. Both these forms of data are delivered within a zip file. There is also direction towards the website of QGIS, a free and open source geographic information system (QGIS, 2016), where the latest mapping software is downloadable. An initial impression based on this would reasonably assume that fulfilling the desire of the government through the analysis of open crime data is simply a matter of dedicating the time to follow instructions provided.

Yet there are limitations here also. The problem with the analysis stage of data is that there are limited or no instructions. Whilst those who have had a previous exposure to GIS software might feel confident downloading this information and opening it in the mapping software programme, this may not be an entirely straightforward process. There does appear to be proficient guidance on how to use QGIS on the video sharing website Youtube (see VTgeospatial, 2015) however the availability of this instruction is not advertised on the Police.uk website. Instead the onus for empowerment and engagement comes from elsewhere. The case is the same for the raster data, which is visual imagery, required to complement the plotting of crime counts so that the counts can be viewed in context. Raster data is an essential component of crime maps as it essentially forms the backdrop on which crime counts can be viewed, for example street imagery, a neighbourhood estate or a whole country. Whilst the necessity of raster data is not indicated by Police.uk, there are other open data sources which offer the requisite raster data free of charge (see Ordnance Survey, 2016). As mentioned, there is the possibility of downloading raster information from the latest 
mapping technologies (e.g. Google Maps, Bing Maps) via the QGIS programme but this avenue is not made explicit. Evidently there are other organisations willing to offer open data or programmes for public use, however despite claiming to empower engagement in crime prevention efforts (Chainey and Tompson, 2012) the Police.uk website still leaves some of the onus on the individual to search for these materials. The Police.uk website may provide some utility for a user who has a wealthy experience of crime analysis and mapping software but for those who have not, there are important details left unexplained should they wish to inspect this open data more closely.

If the user manages to successfully download the zip file, extract the crime data and acquire the requisite boundary and raster data, there are two further implications to contend with. One is a more pressing issue than the other and involves the coordinate reference system which needs to be set on the QGIS Mapping Program. On the Police.uk website (2016c) the crime counts which are downloadable contain Eastings and Northings, or geographic coordinates, which follow the 'OSGB36' for England and Wales, OSNI52 for Northern Ireland' (ibid). In reality, the coordinate system to which the downloadable crime counts adhere is the coordinate system 'WGS84'. Plotting the downloaded points with the wrong coordinate system selected will mean that the points end up in a location some distance from where you would expect to see them. Furthermore, once plotted, with the correct coordinate system selected, there are number of outliers or crime counts that have not been correctly recorded or have been allocated to the records of the wrong police force. This is displayed by Figure 1.2. This demonstrates that, as well as the issue of missing data, there is another limitation caused by offences being recorded under the wrong jurisdiction. Figure 1.2 depicts crime points for just one month, in one police boundary, and yet there are a significant number of outliers. This issue would only become augmented if analysis was to include additional months' worth 
of data in multiple jurisdictions. Such limitations are likely to reduce the validity of crime analysis since the data set available does not include the entirety of the crime counts that occur within a given boundary. It has been declared that for the public 'to consider doing anything about crime or, at least to frame the questions they ask of those whose job it is to do so - they need an accurate (as opposed to a purely apochryphal or anecdotal) picture of crime activity’ (Sampson and Kinnear, 2009). Currently this accuracy is somewhat lacking.

[Figure 1.2 near here]

[Figure 1.3 near here]

There is then concern over the level of analysis that can be conducted with the use of the data set provided. Figure 1.4 conveys a visual representation of the Police.uk data plotted using QGIS software. If viewed in conjunction with Figure 1.2, which is a print screen of what the Police.uk (2016a) website offers after entry of a postcode, it can be discerned that there is little difference between the crime map provided by Police.uk (ibid) and one constructed independently. There is a possibility of adding different neighbourhood boundaries, as has been demonstrated, and perhaps mapping crime counts from multiple months on the same map. The latter method could be conducive towards a form of 'hotspot mapping' (Chainey et al, 2008) for single or multiple crime types as a means of identifying where police and crime reduction resources might be well-placed (ibid). Beyond this, exploration is limited by a lack of information provided within the downloadable spreadsheets which contain counts of crime. The spreadsheet used to plot Figure 1.4, is provided by Figure 1.5. As can be observed, there is no specification of the type of vehicle crime, there is no time and date of 
the offence and there is no detail about the offence such as offender modus operandi. Without this information, more insightful forms of analysis such as deciphering the awareness space of an offender through crime pattern analysis (Ratcliffe, 2002b) are hindered, as is for instance, the detection of a forager offender through study of levels of near repeat victimisation (Johnson, 2013; 2014) ${ }^{\mathbf{1}}$. The absence of these details provides evidence that there could still be some improvement of 'the credibility of crime statistics in the mind of the public’ (Chainey and Tompson, 2012). Tompson et al (2015), using police recorded crime data to verify Police.uk data, established that there may be great worth in using the latter data set to examine neighbourhood trends for the whole country but there is a stumbling block posed by the absence of time and day of offence. As mentioned, given that Police.uk data is already geomasked, it is not fully intelligible why offence data cannot include at least one of these aspects.

[Figure 1.4 near here]

\section{[Figure 1.5 near here]}

Whilst it is welcome that the data available on Police.uk adheres so closely to privacy guidelines, this means that comprehensive analysis by researchers external to police facilities is constrained. For instance, the study of spatiotemporal patterns of crime as a conduit towards analysis of offender spatial movement is impeded by the lack of precision offered (Kounadi et al, 2013). It has been stated that the “identification of spatial and temporal patterns of crime is one of the most important policy-related developments in contemporary criminological research”' (Block and Fujita, 2013: 151) but this is a process which relies on 
access to precise records of exactly when and where specific crime types occurred. Past research suggests that many offenders maintain a discernible spatial and temporal approach to their offending (Johnson, 2013) but this will not become apparent if the time of the offence cannot be discerned. To refer back to the notion of engagement (Chainey and Tompson, 2012), the public are informed about the frequency and approximate location of some crimes but whether this is accurate enough to promote empowerment for researchers is questionable. Smith and Heath (2014) have suggested that perhaps more useful to the public would be an increase in the frequency of data release from months to perhaps weeks and to specify whether offences occurred during day time or night time hours.

Furthermore, for the researcher, a lack of information about the crime count such as the modus operandi of the offender prohibits offender profiling further. To take the example of burglary from a dwelling, if it is not possible to determine the exact type of residency being targeted or the entry methods used then there is little hope of deciphering serial crimes and potentially useful research. The ability to visualise where crime clusters each month is unlikely to be conducive towards any sophisticated techniques such as the analysis of offender awareness space and risk to particular properties as conducted for example by Davies and Johnson (2015). It is not being disputed here that the Police.uk data gives a flavour of where certain crime types might be prominent; what is being questioned is the level of empowerment this open data provides. Upon consideration of these concerns, the downloadable crime data does not appear to have made a significant amount of progress upon the crime maps originally offered on the Police.uk website (2016a) (through the entry of a UK postcode) and the Apps offered elsewhere. 
A more recent addition to the Police.uk dataset has been the provision of crime outcome status and stop and search data. With regards to the former, the fact that information beyond the location of offences is now provided may be demonstrative of not only an increased accountability of the police, but the criminal justice system more generally. Those who may have been in some way affected by offences, or perhaps have known about offences occurring, can now verify in what respect the perpetrator or perpetrators were brought to justice. This addition has offered opportunities for researchers to conduct insightful investigation. For instance, one line of enquiry could be to examine where crime has been committed by offenders who successfully evaded apprehension and where it has been committed with the suspect suitably identified. Although an advancement, it needs to be questioned whether the availability of this information is known about and what impact (if any) this has had on levels of satisfaction with crime prevention agencies. The case is similar for the addition of stop and search data, another example of useful information being provided above and beyond just the locations at which criminal offences were recorded. For those interested in the volume of stop and searches that occur, who they involve and for what reasons they were carried out, this information may be of some value. Once more, how obtainable this information is for those with an interest in it needs to be further probed. Also to be answered is whether this improves accountability in the eyes of the public. With rich stop and search data now available, the Police.uk site would perhaps do well to provide figures on the number of times this information has been utilised or better still, provide an information sharing facility where public ideas can be shared or discussed. 


\section{$\underline{\text { Conclusion }}$}

Whilst there is some informative material provided and useful additions have been made, limitations with the police recorded data made available by Police.uk remain. In some respects, the crime data lacks nuance and could be counter-intuitive on the grounds of the quality of the data and the functionality of the site. The statement that the crime data provided is ‘descriptive but not predictive of crime’ (Byrne et al, 2013) still holds some validity in that it is doubtful whether this data permits sophisticated research outside of police intelligence hubs. Nevertheless, there has also been supplementary data such as stop and search data or neighbourhood policing priorities that are likely to have proved insightful. Feedback could be ascertained from members of the public, with regards to the level of interest in these forms of data and whether they fulfil the expectations of the user.

It was demonstrated that for the research community, there are limitations upon the level of exploratory analysis of police recorded crime data that can be conducted beyond the software already accessible on the Police.uk interface. This leaves a disparity between the ambitions of the UK government and the quality of the resources which it has put in place for researchers to achieve them. Future research in this area should pay attention to the level of information provided on Police.uk and to explore more complex forms of analysis if the provision of data is further improved for instance with the addition of further crime types or approximate times of occurrence. Furthermore, we have touched upon the importance of linking the present situation in England, Wales and Northern Ireland with other countries as a means of advancing the use of open data more globally. A worthwhile line of enquiry could be to investigate whether any country has found a fine balance between the demands of transparency and privacy which could serve as an exemplar for others. 
By way of summary, the objective of this piece has been to evaluate whether in its current format the Police.uk provides accountability and the useful service for which it was established. The objective here has not been to challenge the purpose of having a Police.uk website and the information it provides nor has the intention of this piece been to suggest that the Police.uk website should provide a completely flawless data set. However, as has been outlined, some pressing issues remain with this open data with regards to the level of accountability it provides. What should be stressed is that the public are more likely to become informed, engaged and empowered if the current standard of open crime data is enhanced whilst not violating privacy regulations. There is scope for further debate which engages with tensions between the provision of open data for sophisticated analysis suitable to meet the needs of researchers, and the need to supply data for the general public that does not stigmatise locations or provoke privacy concerns. The crime data currently available also needs to be complemented with other forms of open source data like the CSEW alongside acknowledgement that suitable guidance is offered by other websites. There is also an exciting opportunity to facilitate discussion or the sharing of ideas or findings between members of the public, researchers or both, based on the open data provided. Efforts to provide open crime data and an endeavour to become more transparent should be deemed highly desirable. What must ensue is for some of the discussed limitations to be overcome and then the government might be able to better claim that efforts to become transparent and empower have been realised.

\section{Acknowledgements:}

We would like to thank Professor Ken Pease for his comments on an earlier draft. Any errors and omissions are down to us. 


\section{Notes:}

1. The forager offender theory holds that like the animal forager who will minimize effort and return to the same fruitful patch, so the forager offender will continue to offend in a particular location until resources are exhausted or risk outweighs benefit. (For further explanation see Johnson 2013; 2014).

\section{References:}

Arthur, C., (2011) ‘Crime Maps Are “Worse than Useless”, Claim Developers’, The Guardian (online) 2 February, Available at:www.theguardian.com/technology/2011/ feb/02/uk-crime-maps-developers-unhappy, [Accessed 01.03.16].

BBC News, (2014) Police fail to record one in five of all crimes reported to them, says report. (online) Available at: http://www.bbc.co.uk/news/uk-30081682 [Accessed 25.08.17].

Bizer, C., (2009) The Emerging Web of Linked Data, IEEE Intelligent Systems, 87-92.

Block, S., and Fujita, S., (2013) Patterns of near repeat temporary and permanent motor vehicle thefts, Crime Prevention and Community Safety, 15, 2, 151-167

Byrne Evans, M., O’Hara, K., Tiropanis, T., Webber, C., (2013) Crime Applications and Social Machines: Crowdsourcing Sensitive Data. Southampton: University of Southampton. 
Chainey, S., Tompson, L., and Uhlig, S., (2008) The Utility of Hotspot Mapping for Predicting Spatial Patterns of Crime, Security Journal, 21, 4-28.

Chainey, S., and Tompson, L., (2012) Engagement, Empowerment and Transparency: Publishing Crime Statistics using Online Crime Mapping, Policing, 6 (3) 228-239.

Chakraborti, N., and Garland, J., (2015) Hate Crime: Impact, Causes and Responses, $2^{\text {nd }}$ Edition. London: Sage.

Cooke, L., and Sturges, P., (2009) Police and media relations in an era of freedom of information, Policing and Society, 19 (4) 406-424.

Davies, T., and Johnson, S. D., (2015) Examining the Relationship Between Road Structure and Burglary Risk Via Quantitative Network Analysis, Journal of Quantitative Criminology, 31 (3) pp481-507.

Ericson, V., and Haggerty, K. D., (1997) Policing the Risk Society. Oxford: Oxford University Press.

Family Watchdog, (2016) Family Watchdog (online) Available at: http://www.familywatchdog.us/Default.asp [Accessed 01.03.2016].

Fernandez, M., Cano, A. E., and Harith, A., (2014) Policing engagement via social media. In: City Labs Workshop - SocInfo 2014, 10-13 Nov 2014, Barcelona, Spain. 
Gov.uk., (2013) Crime and policing - guidance: Find out if a person has a record for child sexual offences (online) Available at: https://www.gov.uk/guidance/find-out-if-a-person-hasa-record-for-child-sexual-offences. [Accessed 01.03.17]

Gov.uk., (2016) Vehicle Offences. (online) Available at:

https://www.gov.uk/government/uploads/system/uploads/attachment_data/file/513285/countvehicle-april-2016.pdf [Accessed 01.02.17)

Gov.uk., (2017) The National Crime Recording Standard (NCRS): what you need to know. (online) Available at:

https://www.gov.uk/government/uploads/system/uploads/attachment_data/file/116269/ncrs.p df [Accessed 25.08.17]

Gov.uk., (nd) Theft Act Offences. (online) Available at: http://www.cps.gov.uk/legal/s_to_u/theft_act_offences/\#a09b [Accessed 01.02.17]

Graham, C. (2012). Anonymisation: managing data protection risk code of practice. Information Commissioner's Office (online) Available at: http://eprints.soton.ac.uk/345821/1/anonymisation_code.pdf [Accessed 01.03.2016]

Grove, L., and Thomas, S., (2014) What’s the Future for Heritage Crime Research? In. Grove, L., and Thomas, S., (eds) Heritage Crime: Progress Prospects and Prevention. Chapter 13. Basingstoke: Palgrave Macmillan. 
HMIC, (2014) Crime-recording: making the victim count. (online) Available at: http://www.justiceinspectorates.gov.uk/hmicfrs/wp-content/uploads/crime-recording-makingthe-victim-count.pdf [Accessed 25.08.17]

HMIC, (2015) Crime data integrity: An inspection of British Transport Police. (online) Available at: https://www.gov.uk/government/uploads/system/uploads/attachment_data/file/457658/british -transport-police-crime-data-integrity.pdf. [Accessed 01.03.2016]

HMIC, (2016) The Crime Recording Process (online) Available at: https://www.justiceinspectorates.gov.uk/hmic/our-work/crime-data-integrity/crimerecording-process/ [Accessed 01.03.2016].

HMICFRS., (2017) Leicestershire Police: Crime Data Integrity inspection 2017. (online) Available at: http://www.justiceinspectorates.gov.uk/hmicfrs/publications/leicestershirepolice-crime-data-integrity-inspection-2017/ [Accessed 06.10.2017]. Home Office (2016) Counting Rules for Recorded Crime. (online) Available at: https://www.gov.uk/government/uploads/system/uploads/attachment_data/file/513285/countvehicle-april-2016.pdf [Accessed: 03.05.2016].

ICO, (2012) Crime-mapping and geo-spatial crime data: privacy and transparency, (online) Available at: https://ico.org.uk/media/for-organisations/documents/1543/crime_mapping.pdf [Accessed 01.03.2016]. 
Janssen, M., Charalabadis, Y. and Zuiderwijk, A., (2012) Benefits, Adoption Barriers and Myths of Open Data and Open Government, Information Systems Management, 29: 258-268.

Johnson, S., (2013) The space/time behaviour of dwelling burglars: Finding near repeat patterns in serial offender data, Applied Geography, 41, 139-146.

Johnson, S. D., (2014) How do offenders choose where to offend? Perspectives from Animal Foraging, Legal and Criminal Psychology, 19, 193-210.

Kindynis, T., (2014) Ripping up the Map: Criminology and Cartography Reconsidered, British Journal of Criminology, 54, 222-243.

Kounadi, O., Lampoltshammera, T. J., Leitner, M., Heistracher, T., (2013) Accuracy and privacy aspects in free online reverse geocoding services, Cartography and Geographic Information Science, 40 (2) 140-153.

Kounadi, O., Bowers, K., and Leitner, M., (2015) Crime Mapping On-line: Public Perception of Privacy Issues, European Journal of Criminal Policy, 21: 167-190.

Kwan, M., Casas, I., and Scmitz, B. C., (2004) Protection of Geoprivacy and Accuracy of Spatial Information: How Effective Are Geographical Masks?, Cartographica, 39 (2) 15-28. 
Legislation.gov.uk (nd) Data Protection Act 1998 (online) Available at:

http://www.legislation.gov.uk/ukpga/1998/29/contents [Accessed 25.08.2017].

Macdonald, Z., (2002) Official Crime Statistics: Their Use and Interpretation, The Economic Journal, 112 (477) 85-106.

Monaghan, M., \& Prideaux, S. (2016). State Crime and Immorality: The Corrupting Influence of the Powerful. Policy Press.

Office for National Statistics, (2016a) Crime and Justice, (online) Available at: https://www.ons.gov.uk/peoplepopulationandcommunity/crimeandjustice [Accessed: 01.03.2016].

Office for National Statistics, (2016b) Statistical Bulletin: Crime in England and Wales: Year ending September 2015 (online) Available at:

https://www.ons.gov.uk/peoplepopulationandcommunity/crimeandjustice/bulletins/crimeinen glandandwales/yearendingseptember2015\#accuracy-of-the-statistics [Accessed: 01.03.2016].

Ordnance Survey (2016) Mapping Data and Geographic Information from OS. (online) Available at: https://www.ordnancesurvey.co.uk/opendatadownload/products.html [Accessed 01.03.2016].

Police.uk (2015) Stop and Search data now on Police.uk, (online) Available at: https://www.Police.uk/news/stop-and-search-data-published-policeuk/ [Accessed 01.03.17] 
Police.uk (2016a) Crime and policing in England and Wales, (online) Available at: https://www.Police.uk/ [Accessed: 03.05.16].

Police.uk (2016b) Annual Data Requirement, (online) Available at: https://data.Police.uk/data/annual-data-requirement/ [Accessed: 03.05.2016]. Police.uk (2016c) About data.Police.uk (online) Available at: https://data.Police.uk/about/ [Accessed 01.03.16].

Poulsen, E., Kennedy, L. W., (2004) Using Dasymetric Mapping for Spatially Aggregated Crime Data, Journal of Quantitative Criminology, 20 (3) 243-262.

QGIS., (2016) QGIS: A Free and Open Source Geographic Information System (online) Available at: http://www.qgis.org/en/site/ [Accessed 01.03.2016].

Quinton, P., (2011) The impact of information about crime and policing on public perceptions: The results of a randomised controlled trial. National Policing Improvement Agency. January, 2011.

Rape Crisis England and Wales, (2016) Sexual Violence: Statistics, (online) Available at: http://rapecrisis.org.uk/statistics.php [Accessed 01.03.2016].

Ratcliffe, J., (2002a) Damned if you don’t: damned if you do: Crime Mapping and its implications in the real world, Policing and Society, 12 (3) 211-225. 
Ratcliffe, J., (2002b) Aoristic Signatures and the Spatio- Temporal Analysis of High Volume Crime Patterns, Journal of Quantitative Criminology, 18 (1) 23-43.

Sampson, F., and Kinnear, F., (2009) Plotting Crimes: Too True to Be Good? The Rationale and Risks behind Crime Mapping in the UK, Policing, Volume 4, Number 1, pp. 15-27

Shadbolt, N., O’ Hara, K., Berners-Lee, T., Gibbins, N., Glaser, H., Hall, W., (2012) Linked Open Government Data. [pdf] IEEE Intelligent Systems. Available at: http://ieeexplore.ieee.org/stamp/stamp.jsp?arnumber=6171150 [Accessed 01.03.2017].

Sherman, L., Neyroud, P. W., and Neyroud, E., (2016) The Cambridge Crime Harm Index: Measuring Total Harm from Crime Based on Sentencing Guidelines. Policing, 10 (3) 171183.

Smith, A., and Heath, T., (2014) Police.uk and Data.Police.uk: Developing Open Crime and Justice Data for the UK, Jedem, 6 (1) pp 87-96.

Tompson, L., Johnson, S., Ashby, M., Perkins, C., and Edwards, P. (2015) UK open source crime data: accuracy and possibilities for research, Cartography and Geographic Information Science, 42 (2) 97-111.

UK Statistics Authority (2010) Overcoming Barriers to Trust in Crime Statistics: England and Wales. Monitoring report 5. London: UK Statistics Authority. 
Walby, S., and Allen, J., (2004) Domestic violence, sexual assault and stalking: Findings from the British Crime Survey, Home Office Research Development and Statistics Directorate, 276, 1-132.

Weisburd, D. and McEwen, T. (1998). Crime Mapping and Crime Prevention. New York: Criminal Justice Press.

VTgeospatial, (2015). Introduction to QGIS (Video Online) Available at: https://www.youtube.com/watch?v=WAbOR_E2xtI [Accessed 01.03.2016] 